\title{
Science communication podcasting in Brazil: the potential and challenges depicted by two podcasts
}

\author{
MARCOS V. DANTAS-QUEIROZ ${ }^{1}$, LIA C.P. WENTZEL ${ }^{1}$ and LUCIANO L. QUEIROZ ${ }^{2}$ \\ ${ }^{1}$ Universidade Estadual Paulista/UNESP, Instituto de Biociências, Av. 24-A, 1515, Bela Vista, 13506-900 Rio Claro, SP, Brazil \\ ${ }^{2}$ Dragões de Garagem Podcast, Rua do Mercado, 19, Quadra 5, Lote 1, 74523-330 Goiânia, GO, Brazil
}

Manuscript received on June 7, 2017; accepted for publication on October 31, 2017

\begin{abstract}
Podcasts - online distributed audio files - are easy access and production media, which can be used for Scientific Communication (SC) but few are presented in Portuguese. The objective of this work is to perform a case study with data from a survey for two Brazilian SC podcasts (Dragões de Garagem and Fronteiras da Ciência) to evaluate the increase of science podcast media in Brazil, the involved potential, their advantages, shortcomings, and perspectives. We noted an increase of listeners over the years, probably due to the internet popularization and the massive increase of mobile phones. Scientific content is underexplored, despite the great interest of the public. Humorous and informal podcasts are the most appealing to the public and they usually listen to them on informal educational sites. The majority of the public is from the South and Southeast regions, they are young male adults with undergraduate or graduate degrees. SC podcasts, despite their potential to communicate science, still have shortcomings to overcome. Nevertheless, independent initiatives can solve this difficulty, making possible for the media to reach a varied audience, affecting different groups that would not have interest in a specific content before, or even the access itself to the scientific knowledge.
\end{abstract}

Key words: Internet, podcast, science communication, online survey.

\section{INTRODUCTION}

Nowadays more than just communicating science among their peers, scientists play the primordial role to democratize the access to scientific knowledge for the whole population through Science Communication (SC) (Poliakoff and Webb 2007, Bueno 2010). Nonetheless, $\mathrm{SC}$ is a branch in which not all scientists head for, for many reasons, mainly those related to the inherent technical difficulties

Correspondence to: Marcos Vinicius Dantas-Queiroz

E-mail: marvin.danque@gmail.com to content distribution or the lack of abilities and essential tools for the undertaking (Brownell et al. 2013). Many scientists still consider SC as an activity of little importance for their careers.

Science communication carried out by large mainstream media has the obvious advantage of its broad propagation, and in developing countries, it is by these media that SC happens with more intensity (Massarani 2015). In these kinds of media, generally, a journalist intermediates the source of the content (the scientist) and the public. On the other hand, many scientists end up avoiding 
this type of approach for it is common that their statements and provided information be distorted, generating noise between the actual content and the public's knowledge (Weigold 2001, Bueno 2010). Consequently, independent ways of trying to communicate science should be used.

In Brazil, there is a long record of science communication, especially associated with scientific societies and public institutions (Massarani and Moreira 2016). The few scientists that communicate their own research, as well as the ones from their peers, have been seen through books, lectures and other means of communication. Nevertheless, with the advent of the Web 2.0, the Internet made possible a greater range of SC activities (Brumfiel 2009). As in many other countries in the world, the Internet use in Brazil for SC seems to be an excellent means for its consolidation, because its access has been increasing to high levels, where more than half of the Brazilian population has already access to the world wide web (IBGE 2014). This significant increase in the use of online resources promotes a decrease in the use of other established means of communication, as in the United States of America, where it is noticeable the migration of the search for information sources from the TV and the Radio to the Internet (Nisbet and Scheufele 2009). With the rise in the number of online users, attempts to mix traditional media of SC and new approaches have been arising in the course of this century's first decade.

At the end of the nineties and beginning of the two-thousands, the blogs (contraction from weblogs) revolutionized the way how science could be disseminated through the online environment. Scientists, professors, journalists, undergraduate and graduate students could publish their discoveries through their "own voice" or comment and express their opinion about published papers, providing the public an alternative to the means of mass communication (Wilkins 2008, Takahashi and Tandoc Jr 2015). Scientific blogs, however, can be opening space to other audiovisual media like vlogs (video blogs) and podcasts, tools that enhance even more the capacity of communicating science, mainly to a young public which uses these media as a primary source of information (Beaujon 2012, Fausto et al. 2017).

Created at the beginning of the 21 st century by the fusion of the words broadcast and iPod, Apple's most popular media player, Podcasts are Internet-distributed files that can be reproduced on computers, iPods, smartphones or other portable players (Jham et al. 2008). One of the greatest trump cards of this kind of media is its relative ease of creation, accessibility, and propagation. Anyone that has access to a computer with a microphone, recording software and the Internet has the capacity of producing this kind of content.

These media have been extensively employed in educational contexts, especially in higher education and in the learning of new languages due to their great interaction plasticity: after downloading the file, the public has access to information in non-usual education environments, such as their own home, gym, car, bus, etc. The availability of content on demand without being necessarily tied to a location and to a specific period is very attractive (Barros and Menta 2007, Jham et al. 2008, E.P.A. Freire, unpublished data).

Podcasts dedicated to SC are much less frequent than the ones dedicated to entertainment, for example, despite the aforementioned advantages of this medium. There are well-established Podcasts such as the Radiolab (WNYC, New York, NY, EUA), a radio program made available in Podcast format, and the Startalk, presented by the astrophysicist Neil deGrasse Tyson (Curved Light Productions). Eminent scientific journals also develop their own Podcasts, as Science (Science Podcast, American Association for the Advancement of Science - AAAS) and Nature (Nature Podcast, Nature Publishing Group - NPG). 
All these media have a large captive audience and are presented in English.

In a different manner, SC Podcasts presented in Portuguese are produced in an informal and independent fashion, like the Dragões de Garagem, Scicast, Rock com Ciência, Alô, Ciência? and PODEntender. These are all formed by a team of undergraduate and graduate students and professors, or are radio programs made available in Podcast format, such as the Fronteiras da Ciência, coordinated by professors from the Federal University of Rio Grande do Sul (UFRGS). Science communication magazines in Portuguese also have their own Podcasts, as the Revista FAPESP (Pesquisa Brasil), from the São Paulo Research Foundation, and the Ciência Hoje (Estúdio $\mathrm{CH}$, now interrupted), which normally carry out interviews with researchers about their work.

Since podcasts are easy-to-produce media and easy to make contents accessible to the general public, they are tools with a great potential for SC (Picardi and Regina 2008, Hu 2016). However, there are few papers showing this potential and none in Brazil, as far as we know. Therefore, in this paper, we will demonstrate the increase of podcast media in Brazil, the involved potential in this form of SC, who, how and when users listen to SC podcasts, the advantages and shortcomings and the perspectives for the media, based on data from a survey for two Brazilian science communication podcasts.

\section{MATERIALS AND METHODS}

The analyzed data were obtained from a survey entitled PodPesquisa 2014 and had 16,197 participants. These data were not originally collected by us and are available on the website http://podpesquisa.com.br/, as a Creative Commons 4.0 license. The PodPesquisa 2014 edition's questionnaire was available to be answered for a period of three months (February $1^{\text {st }}$ to April $30^{\text {th }}$ of 2014), comprising 27 questions related to behavior, preferences and listeners' demography (see Translation of the Podpesquisa 2014 Results - Supplementary Material). The survey was announced by many podcasts broadcasted in Portuguese and also on social networks (Facebook and Twitter), requesting the public to answer voluntarily to the stipulated questions.

While filling out the questionnaire, the participants were questioned about which podcasts did they listen to, making possible to research organizers to filter the answers by the podcasts' names and so individualizing the obtained data. Thus, we have contacted SC podcasts known to us until 2014, requesting voluntary availability of their individual PodPesquisa 2014 data. From the three contacted podcasts, it was possible to obtain data regarding two SC podcasts, Fronteiras da Ciência (FdC - http://www.ufrgs.br/frontdaciencia/) and Dragões de Garagem (DdG - http:// dragoesdegaragem.com). From these, 473 and 325 listeners from the total of participants indicated that they listened to the podcasts FdC and DdG, respectively. Therefore, in the present paper, these podcasts were used as references in SC podcasts in Portuguese in Brazil (see Supplementary Material).

We also used primary data from DdG podcast, as the number of downloads per episode, the average number of downloads per episode and the sum of downloads per month. These data were useful to improve the discussion about the increase in SC podcasts and the analysis of episodes with a "pop culture" approach. The data were collected from DdG database on September $3^{\text {rd }}, 2017$.

Similar editions of the PodPesquisa were also carried out in 2008 and 2009, with a total of 436 and 2,487 participants, respectively. Data from all editions were employed for the analysis related to the potential of the media in Brazil. The listeners' demography was performed using only the data from 2014 since this was the first edition of the 
research in which SC podcasts were included. With the results in hands, we investigated aspects of the increase and potential of the media in $\mathrm{SC}$, the demography and preferences of the sampled public and the difficulties faced and future perspectives.

\section{RESULTS AND DISCUSSION}

\section{INCREASE AND MEDIA POTENTIAL}

In the three performed editions of the Podpesquisa, we observed an increase in the number of survey participants. This expansion probably corresponds to an increase in the number of podcasts' listeners in Brazil, since a large part of the respondents started listening to podcasts after the PodPesquisa edition, in 2010 (Figure 1). However, there are more long-time listeners of $\mathrm{FdC}$, probably due to its traditional radio format, making it recognizable to a wider audience.

The general pattern of increase in listeners in the last few years of the survey (2010-2014) might be associated with the progressive acknowledgment of what podcast format is about and the gradual increase in the Internet access in Brazil, mainly through mobile network (Brossard 2013, IBGE 2014, The World Bank Group 2017).

The increase in the number of people that have mobile phones is an important point since this is one of the main forms of obtaining and

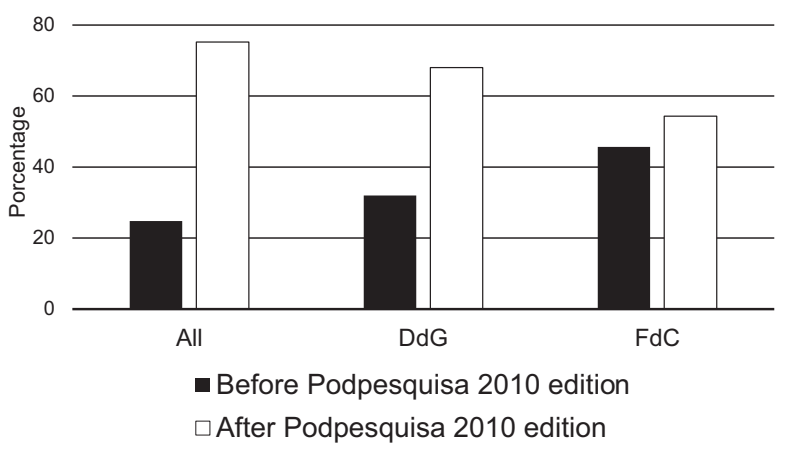

Figure 1 - The period when the participants started to listen to podcasts for the SC podcasts Dragões de Garagem (DdG, $\mathrm{n}=$ 325), Fronteiras da Ciência ( $\mathrm{FdC}, \mathrm{n}=473)$, and the general mean for Brazilian podcasts (All, $\mathrm{n}=16,197$ ). listening to podcasts (Blubrry 2016). In a recent research, the Brazilian Institute of Geography and Statistics (IBGE) pointed out that in 2014 around 136 million Brazilians had a mobile phone (IBGE 2014), bringing up more than half of the Brazilian population.

Nevertheless, mobile network and mobile devices availability are only means, not the continuous and dominant factor for the implementation and solidification of podcasts as a tool for SC. Science communication is a complex system of communication where not only one or two underlying reasons are associated with the public's adherence. The audience has many and different motivations to seek for scientific information, and trying to reach it requires multiple techniques and approaches (Brossard 2013).

Inside the universe of the "podosphere" (It is how the existing universe of podcasts is called), programs with subjects related to entertainment such as humor, television, video games, comic books, movies and other items of the "pop culture" are the most produced and consumed contents. However, a great amount of the PodPesquisa 2014 interviewees considered that these subjects are over-explored (Figure 2a).

On the other hand, the proportion of interviewees that considered the programs with scientific and technological subjects overexplored was low, around 5.21\% and 14.04\%, respectively. Nonetheless, when questioned about which podcasts' subjects they normally listened to, $59.42 \%$ of the interviewees said that they listened to programs with technological subjects and $42.25 \%$ to programs with scientific subjects, remaining in the third and seventh position among the related subjects, respectively (Figure 2b).

This low exploration of the subject and the high number of listeners interested in scientific and technological subjects is an indication of the demand for programs with scientific themes. The Brazilian population's preference for audio- 


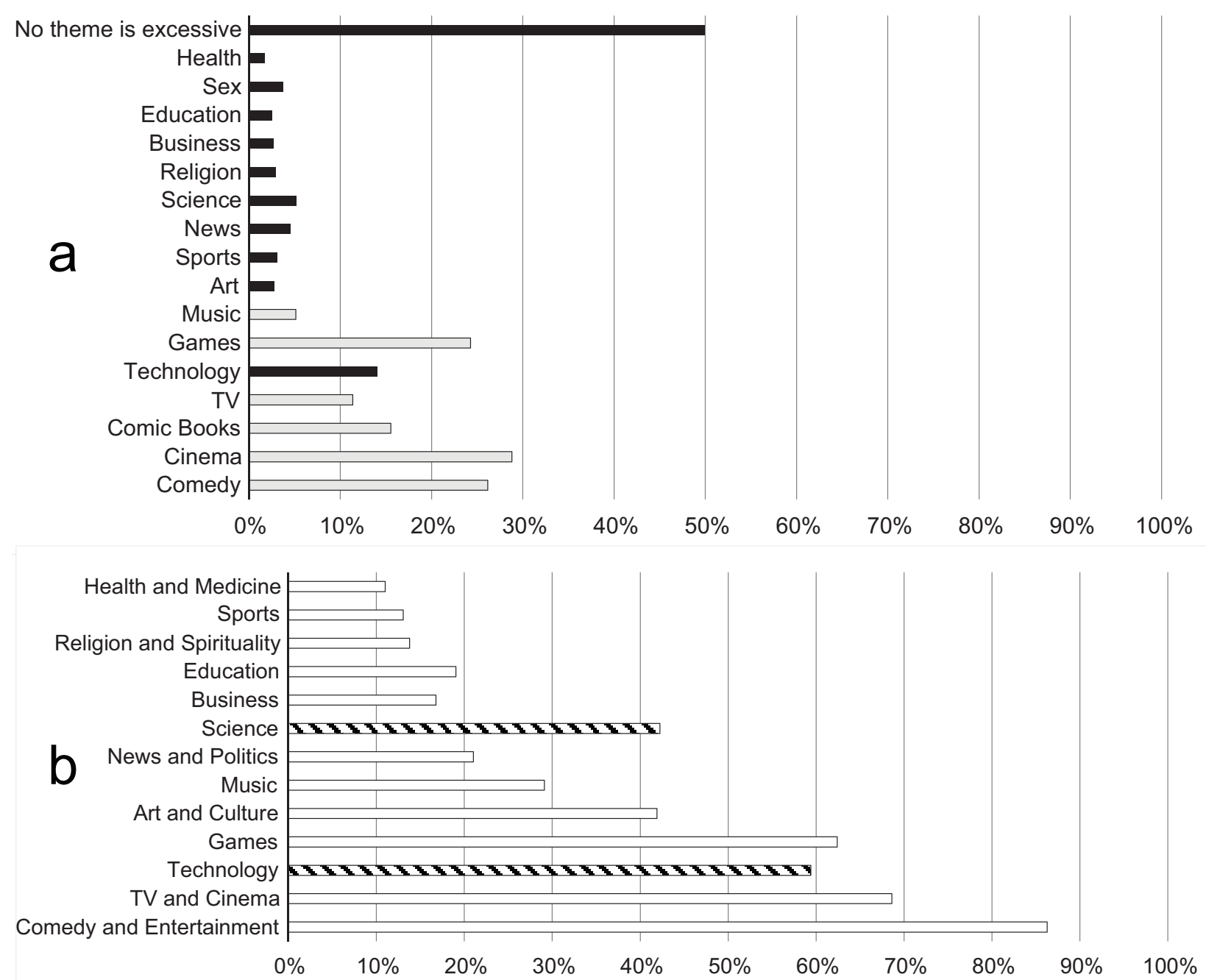

Figure 2 - a) Overexplored subjects in Podcasts, according to PodPesquisa. Topics in gray relate to the pop culture and are among those most consumed; b) Most consumed podcast subjects, according to the PodPesquisa. Pattern bars show the scientific subject.

visual media consumption over the written media (SECOM 2016), and the gradual increase in the use of podcasts in Brazil, added to the interest and to the search for content in SC in the Internet (Laplane et al. 2015) form an important means to talk about science with the lay public in Brazil.

\section{PODCASTS' FORMAT AND CONTENT}

Trying to understand which attributes most draw the public's attention, the content and the form of how podcasts are broadcasted are important factors to be noted. Podcasts that use entertainment and have a good production quality are the main points brought up by the interviewees, both for podcasts in general as well as for the SC ones.

Science communication mixed with creativity and the use of humor to convey scientific concepts to young audiences normally presents a great approval by the public (Nisbet and Scheufele 2009), as well as in educational contexts (Pegrum et al. 2015). This strategy, normally in a narrative way, is found in mass media such as TV series and documentaries, movies and books (Dahlstrom 2014). Thus, the language used in podcasts is most of the time considered informal, aiming at the increasing attraction of its majority audience: adults 
and young adults. The range of some episodes from the podcast DdG is a good example of the efficacy of using pop culture contents to explain scientific concepts, as genetic engineering in movies (>20,500 downloads), Pokémon's science $(>17,300$ downloads) and two episodes about the biology (>19,800 downloads) and the physics $(>21,600$ downloads) present in the movies of the Star Wars series. These "pop culture" episodes had similar or more downloads than the average number of downloads of non-pop culture episodes from $\operatorname{DdG}(18,768 \pm 3,286$ downloads).

Despite the preference in the use of humor and informality as an attraction, comedy and the satirical approach in SC are still a delicate issue, which needs to be employed carefully in the production of SC podcasts. The informal language can also bring an exaggeration in the vulgar way of speaking, repelling certain spectators (Pazza 2015). In studies related to the communication of climatic changes, for example, humor is not always the best choice to develop a trust relationship with the public; in this case, the best strategy would be the commitment of the scientist in a vulnerability relationship, e.g., admitting mistakes, empowering the public to seek for scientific knowledge by themselves and making himself/herself available to discuss delicate issues with the audience (Goodwin and Dahlstrom 2014). Despite humor normally builds affective bonds between the public and the scientist, this same bond can exclude groups that could not understand the employed humor, excluding them from understanding the information (Riesch 2015). It is the speaker's duty to understand his/her public and to blend the tone of his/her own discourse.

The preference regarding the length of podcast episodes in Brazil is noticeable. Educational podcasts normally tend to be produced at short intervals, with a maximum of five minutes (Mcgarr 2009). However, longer episodes varying between 60-90 minutes were the favorites among the interviewees (47.55\%). This pattern was also found in the two SC podcasts analyzed, DdG (45.23\%) and $\mathrm{FdC}(36.99 \%)$.

In spite of the result indicating this preference by the Brazilian public, it is worth to make an exception regarding the PodPesquisa's format: the research participants already have the habit of consuming podcast media, since the foundation of this public occurred from long-length programs. Science communication programs benefit from the long-length format due to the possibility of better working and developing more complex issues.

Nevertheless, considering the people that do not have this habit, long-length programs can represent an obstacle for them to start consuming the media. Programs with medium (30-60 minutes) or short length ( $<30$ minutes) episodes can be a good strategy for the attraction of new listeners for SC podcasts and for other categories of podcasts.

\section{INTERACTION AND USE OF PODCASTS}

In $\mathrm{SC}$ podcasts there is a great ease in interacting with the content producers' of these programs, which in turn elicits a democratic dialogue between listeners and producers and also between the audience itself (Greco 2005, Birch and Weitkamp 2010). Discussions are stimulated, questions are asked and other comments generate a rich feedback between the two parts, via e-mail, social networks or in the podcasts' own website.

The SC podcasts here analyzed are produced by undergraduate and graduate students, professors and researchers from diverse science areas, making possible to get the scientists themselves together with other academics and the lay public. This greater interaction and accessibility allows the public to participate in and to embrace scientific discussions, not to mention the production itself and communication of the scientific content through social networks (Facebook, Twitter, etc.), blogs, videos (YouTube) and audio (podcasts) (Brossard 2013, Dudo 2015). 
The use of podcasts in non-formal places for the education and popularization of science (i.e., at home, in means of transportation, the gym, etc.) breaks limits with the physical structure of the site. The interviewees stated that they consumed podcasts at home $(45.93 \%)$, on traffic $(34.47 \%)$ and in their workplace $(18.86 \%)$, rarely at school/college $(0.74 \%)$. Nevertheless, the attention driven towards the program is in the majority of cases shared with other activities; around $55.94 \%$ of the interviewees listened to programs with shared attention while they moved around, did domestic chores, physical activities, etc. Distribution methods of SC audiovisual materials, such as DVDs and online videos, require the commitment of the spectator in situating himself/herself in a specific place, usually with a high level of attention. However, the ease in obtaining the podcast's file (usually distributed in MP3 - MPEG-1/2 Audio Layer 3 format) and listening to it in different environments, including when the listener is moving, is also a strong point for using podcasts in SC (Junior and Coutinho 2007, E.P.A. Freire, unpublished data). The possibility of moving the audio backward to listen again to some part that was not well understood or listening to the audio again can remedy any occasional misunderstandings.

\section{SAMPLE LISTENERS' PROFILE}

Demographic data related to the profile of podcast listeners that had responded the survey, such as residence, age, level of education, gender and profession were also analyzed in the PodPesquisa 2014.

The states from the Southeast and South regions were the ones with the highest percentages of listeners (Supplementary Material). This is not a surprising attribute since these are the most economically developed regions in the country and the ones with the highest educational level, points that facilitate the access to this kind of media (IBGE
2010). This can be correlated to a historical context since over time the majority of the SC efforts in Brazil were centralized in the richest states of the country (Massarani and Moreira 2016). Despite the podcast media has the potential to reach farther regions by a simple click, the geographical obstacle also rules, even in online media.

Among the interviewees who listen to the SC podcasts in the study, the majority (DdG $-70.31 \%$; FdC $-84.36 \%$ ) declared to have an undergraduate or a graduate degree, regarding schooling. This higher educational level found in the public that consumes SC podcasts also runs into their age group.

Young people and adults are the public that most consume podcasts, especially teenagers and university students between 15-29 years old (average $=25.09$ years old) (Figure 3). Amongst SC podcasts this pattern rises subtly for the DdG due to a higher number of listeners between 15 and 34 years old (average $=26.46$ years old). On the other hand, the listeners of the podcast FdC are older and are placed between 20 and 39 years old (average $=30.01$ years old). This difference between the two analyzed podcasts can be explained by the difference in the profiles of the podcasts' content producers. The FdC is produced by professors and approaches the issues in a formal and deeper way. The DdG, in contrast, is produced by graduate students and the issues are approached in a more relaxed manner, using issues that are closer to the young public.

A surprising attribute is the predominance of male podcast listeners (87.31\%), mainly when we analyze SC podcasts in which the average number is even higher ( $\mathrm{DdG}-92.33 \%, \mathrm{FdC}-91.75 \%$ ) (Figure 4). This listeners' profile follows a similar pattern to that of people who search for scientific issues on the Internet (Anderson et al. 2010, Brossard 2013), where there is a male and a higher educational level predominance. 


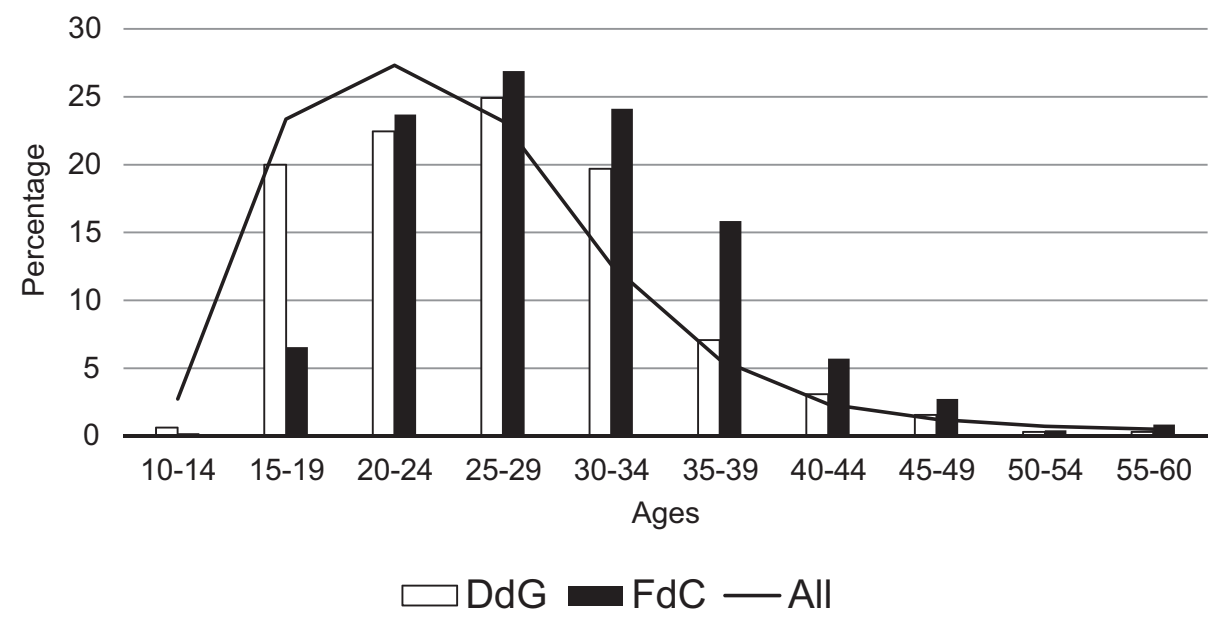

Figure 3 - Percentage of listeners according to age for the SC podcasts Dragões de Garagem $(\mathrm{DdG}, \mathrm{n}=325)$, Fronteiras da Ciência $(\mathrm{FdC}, \mathrm{n}=473)$, and the general mean for Brazilian podcasts (All, $\mathrm{n}=16,197)$.

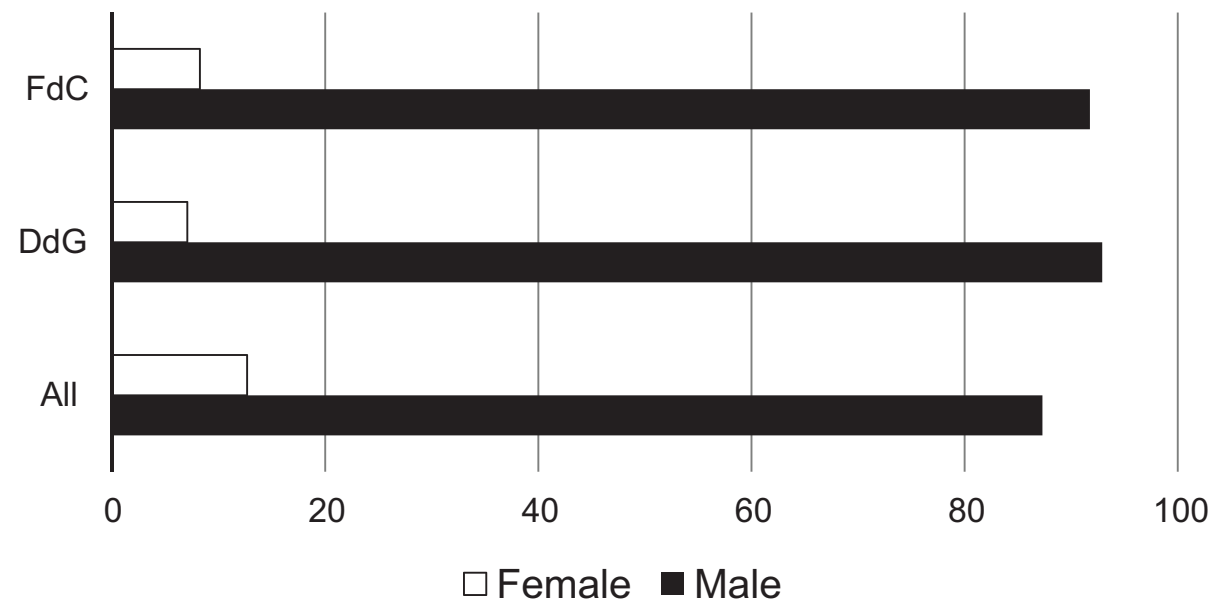

Figure 4 - Listeners' gender in each of the SC podcasts analyzed and in podcasts in general. Fronteiras da Ciência (FdC, $\mathrm{n}=473)$; Dragões de Garagem $(\mathrm{DdG}), \mathrm{n}=325)$; general mean for Brazilian podcasts (All, $\mathrm{n}=16,197)$.

The great participation in the creation and consumption of scientific content in other Internet media by male representatives was already observed in other studies (Anderson et al. 2010, Brossard 2013, Mahrt and Puschmann 2014, Fausto et al. 2017). An explanation for this pattern runs into the listeners' professional areas, which are in part related to the areas of engineering and technology (39.87\%) (Supplementary Material). Historically the fields related to the informatics, despite the numerous and inestimable female contributions (i.e., Ada Lovelace, Margaret Hamilton), had a greater male presence (Bratteteig and Verne 1997, Bratteteig 2008). Possibly the members of these professional groups that are greatly represented by men tend to spread the content only among their peers through online media, social networks, and personal recommendations according to Figure 5, making the propagation of the media unbalanced for the female public.

Nevertheless, the low podcast consumption by female listeners is alarming. If we consider 


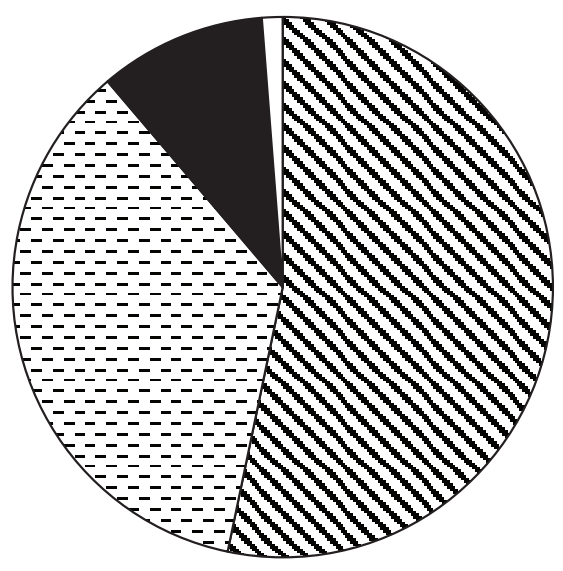

\section{వ Online media $\quad$ Recommendation - Social media $\quad \square$ Traditional media}

Figure 5 - Media in which the first contact with podcasts occurs, according to PodPesquisa.

that the great public that consumes SC podcasts in Portuguese is formed by university students, females are already a majority in this population and also in the field of graduate studies (Marques 2012). Nonetheless, again, the areas of science, math, computer science and engineering are maledominated (INEP 2015), causing a direct impact on how podcast media is disseminated among their peers (Figure 5). This is an issue that still has to be better investigated, aiming to explain vigorously the discrepancy between genders not only in podcasts but also in the consumption of science communication in other media.

Efforts to get around this problem are being discussed in the "podosphere" itself. Usually, the debates conclude that the search for issues more directed to the female public would possibly attract this public to the podcast media. On the other hand, there is also a repercussion on the creation of information and entertainment podcasts with a female team (i.e., the podcasts Mamilos, PodProgramar, Ponto G), a tendency to add more women to the SC podcast teams and to dedicate episodes to women in science (DdG episodes 22, 73 and 99; FdC episode 11, first season, and the
Scicast Podcast- episodes 17 and 18), aiming to attract part of the female public.

\section{CONCLUSION}

Communicating science through podcasts is a rewarding task, although with obstacles to overcome. Despite the great interest of the sampled group in scientific content, there are few podcasts dedicated to SC. Therefore, the increasing number of listeners over the years associated with the appeal that the Brazilian public has to audiovisual media makes SC podcasts a great trump card to be used. Perhaps podcasts can be yet considered as a restricted media given its great familiarity with only some of the demographic groups and centered to the richest regions of Brazil. Nevertheless, independent initiatives with unique informal and humorous approaches can solve this difficulty, making it possible for the media to be accessible to a varied audience. In this way, it could reach different groups that would not have the interest in a specific content before or even the access itself to the scientific knowledge.

Knowing the public to which podcasts (or any other means of communicating science) are addressed and creating a trustful relationship are fundamental ways for a good approach to science communication. Nisbet and Scheufele's (2009) premise is still very current and guides the process through which podcasts are and should be thought as a tool for communicating science:

'... any science communication efforts need to be based on a systematic empirical understanding of an intended audience's existing values, knowledge, and attitudes, their interpersonal and social contexts, and their preferred media sources and communication channels' (Nisbet and Scheufele 2009: 1767).

With the PodPesquisa it was possible to notice that in most of the times podcasts are discovered and shared through online media, be it through websites, 
blogs or social networks. In this environment, the podcast itself can also be a propagation source of scientific content estimated by the new metrics. As a future perspective, the use of new scientometric approaches allows individual scientists to use the new metrics as measures to determine the impact of their studies, encouraging them to communicate their research results in a more effective way, what could promote their impact in the scientific community. However, to analyze which papers are being communicated by audio could be a hindrance, since altmetrics' analysis usually work by verifying textual sources, holding back verification of the works cited in podcasts. Thus, we recommend podcast creators to pay attention to the fact that they can also contribute by making available on the podcast's website the DOI number of the papers and books cited (when existent), permanent links, authors (ORCID) or any other keyword that can relate to the original source.

\section{ACKNOWLEDGMENTS}

The authors thank Sibele Fausto, Iara Vidal and Dônovan Ferreira Rodrigues for the initial review and tips to the manuscript; the PodPesquisa team for making the data available (Creative Commons); the Fronteiras da Ciência and Dragões de Garagem members for the support and making the data available and, of course, the authors thank all the listeners of Brazilian SC podcasts.

\section{REFERENCES}

ANDERSON AA, BROSSARD D AND SCHEUFELE DA. 2010. The changing information environment for nanotechnology: Online audiences and content. J Nanopart Res 12: 1083-1094.

BARROS GC AND MENTA E. 2007. Podcast: produções de áudio para educação de forma crítica, criativa e cidadã. Rev Econ Política las Tecnol la Inf y Comun IX

BEAUJON A. 2012. Pew: Half of Americans get news digitally, topping newspapers, radio. Poynter: a global leader in Journalism. Available at: https://www.poynter.org/2012/ pew-tv-viewing-habit-grays-as-digital-news-consumptiontops-print-radio/189819/ (accessed May 17, 2017).

BIRCH H AND WEITKAMP E. 2010. Podologues: conversations created by science podcasts. New Media Soc 12: 889-909.

BLUBRRY. 2016. Where are your podcast listeners tuning in? Blubrry has some surprising stats. Available at: http://www. powerpresspodcast.com/2016/05/17/podcast-listenerstuning-blubrry-surprising-stats/ (accessed February 15, 2017).

BRATTETEIG T. 2008. Understanding IT and gender. In: OECD-CERI Conference 'Return to Gender: Gender, Ict and Education', Oslo, p. 2-3.

BRATTETEIG T AND VERNE G. 1997. Feminist, or merely critical? In search of Gender Perspectives in Informatics. In: Moser I and Aas GH (Eds), Technology and Democracy - Comparative Perspectives, Olso: TMV, Norway, p. 59-74.

BROSSARD D. 2013. New media landscapes and the science information consumer. Proc Natl Acad Sci USA 110: 14096-14101.

BROWNELL SE, PRICE JV AND STEINMAN L. 2013. Science communication to the general public: why we need to teach undergraduate and graduate students this skill as part of their formal scientific training. J Undergrad Neurosci Educ 12: E6-E10.

BRUMFIEL G. 2009. Science journalism: Supplanting the old media? Nature 458: 274-277.

BUENO WC. 2010. Comunicação científica e divulgação científica: aproximações e rupturas conceituais. Inf Inf 15 : $1-12$.

DAHLSTROM MF. 2014. Using narratives and storytelling to communicate science with non-expert audiences. Proc Natl Acad Sci USA 111: 13614-13620.

DUDO A. 2015. Scientists, the Media, and the Public Communication of Science. Sociol Compass 9: 761-775.

FAUSTO S, TAKATA R, MORENO NT, APUNIKE AT, BUCCI JLM, DOS SANTOS ACG, SILVA WJR, MATIAS M AND KINOUCHI O. 2017. O estado da blogosfera científica brasileira. Em Questão 23: 274-289.

GOODWIN J AND DAHLSTROM MF. 2014. Communication strategies for earning trust in climate change debates. Wiley Interdiscip Rev Clim Change 5: 151-160.

GRECO P. 2005. What type of Science Communication best suits emerging countries? JCOM 4: 1-6.

HU JC. 2016. Scientists ride the podcasting wave. Science, p. 1-5. Available at: http://www.sciencemag.org/ careers/2016/11/scientists-ride-podcasting-wave (accessed June 2, 2017).

IBGE. 2010. Censo 2010. Disponível em http://censo2010. ibge.gov.br/ (data de acesso 17 de Maio de 2017). 
IBGE. 2014. Pesquisa Nacional por amostra de domicílios: acesso à internet e posse de telefone móvel celular para uso pessoal. Rio de Janeiro: IBGE, 157 p.

INEP. 2015. Resumo Técnico - Censo da Educação do Ensino Superior. Brasília: INEP, p. 80.

JHAM BC, DURAES GV, STRASSLER HE AND SENSI LG. 2008. Joining the podcast revolution. J Dent Educ 72: 278-281.

JUNIOR JBB AND COUTINHO CP. 2007. Podcast em educação: um contributo para o estado da arte. In: Barca A et al. (Eds), Libro de Actas do Congresso Internacional Galego-Portugués de Psicopedagoxía, Coruña: Universidade da Coruña, Spain, p. 837-846.

LAPLANE M, BADARÓ A, FALCÃO D, MOREIRA IC, CASTELFRANCHI Y, RIZZO F, OLIVEIRA I, PAIVA M AND CARRIJO T. 2015. Percepção pública da ciência e tecnologia no Brasil 2015 - Ciência e tecnologia no olhar dos brasileiros. Brasília: CGEE, p. 15.

MAHRT M AND PUSCHMANN C. 2014. Science blogging: An exploratory study of motives, styles, and audience reactions. JCOM 13: A05.

MARQUES F. 2012. Limites da diferença. Revista FAPESP 196: 30-31.

MASSARANI L. 2015. Voices from other lands. Publ Understand Sci 24: 2-5.

MASSARANI L AND MOREIRA IDC. 2016. Science communication in Brazil: A historical review and considerations about the current situation. An Acad Bras Cienc 88: 1577-1595.

MCGARR O. 2009. A review of podcasting in higher education: Its influence on the traditional lecture. AJET 25: 309-321.

NISBET MC AND SCHEUFELE DA. 2009. What's next for science communication? Promising directions and lingering distractions. Am J Bot 96: 1767-1778.
PAZZA R. 2015. Falar palavrão no podcast, pode? Disponível em http://darwin.bio.br/dnacetico/?p=1789 (data de acesso 15 de Março de 2017).

PEGRUM M, BARTLE E AND LONGNECKER N. 2015. Can creative podcasting promote deep learning? The use of podcasting for learning content in an undergraduate science unit. Br J Educ Technol 46: 142-152.

PICARDI I AND REGINA S. 2008. Science via podcast. JCOM 7: 1-4.

POLIAKOFF E AND WEBB TL. 2007. What factors predict scientists' intentions to participate in public engagement of science activities? Sci Comm 29: 242-263.

RIESCH H. 2015. Why did the proton cross the road? Humour and science communication. Publ Understand Sci 24: 768775 .

SECOM. 2016. Pesquisa brasileira de mídia - 2016. Brasília: IBOPE Inteligência, p. 156.

TAKAHASHI B AND TANDOC JR EC. 2015. Media sources, credibility, and perceptions of science: Learning about how people learn about science. Publ Understand Sci 25: 674-690.

THE WORLD BANK GROUP. 2017. Internet consumption. Available at: http://www.worldbank.org/ (accessed May 16, 2017).

WEIGOLD MF. 2001. Communicating science: a review of the literature. Sci Comm 23: 164-193.

WILKINS JS. 2008. The roles, reasons, and restrictions of science blogs. Trends Ecol Evol 23: 411-413.

\section{SUPPLEMENTARY MATERIAL}

Translation of the Podpesquisa 2014 Results 